\title{
Análise das ilhas de calor em um campus universitário no Litoral Norte da Paraíba.
}

\author{
Analysis of the islands of heat in a Campus on the north coast of Paraiba.
}

SILVA, I, A ${ }^{1}$; SANTOS, J, S²; VIEIRA, M, L, S ${ }^{3}$

ingridizinha_91@hotmail.com

\section{Resumo}

As diversas modificações que os ambientes urbanos vêm sofrendo têm proporcionado grandes mudanças nos sistemas climáticos urbanos, e é nesse contexto que este artigo se insere, com o objetivo principal de realizar um estudo do clima urbano, especificamente do campo térmico, dentro do espaço intra-urbano do Campus. Foram definidos 05 pontos de coleta dos dados (Temperatura e UR), em função de diferentes materiais de revestimento do solo, onde foram instalados termohigrômetros. Os experimentos foram realizados durante os períodos de estiagem e o chuvoso. A avaliação da intensidade de ilha de calor foi obtida pela diferença entre a temperatura do ar da área não urbanizada com a urbanizada. Os resultados evidenciaram a formação de ilhas de calor mais expressivas para o mês de janeiro com $4,89^{\circ} \mathrm{C}$ em área urbanizada. A pesquisa também demonstrou a necessidade de uma gestão sustentável do Campus IV que leve em consideração tais parâmetros ambientais para o ordenamento territorial.

Palavras-chave: Climatologia urbana, Ilha de Calor, Uso e Ocupação do Solo

\begin{abstract}
The various modifications that the urban environments are suffering have led to important changes in weather systems, and it is in this context that this article is part, with the main objective to conduct a study of the urban climate, specifically the field shield inside the intra-urban differentials of the Campus. Were defined 05 points of data collection (temperature and $\mathrm{RH}$ ), as a function of different flooring materials from the soil, where they are installed Word-stem hygrometers. The experiments were performed during periods of drought and rainy weather. The evaluation of the intensity of island of heat was obtained by the difference between the air temperature of the area not urbanized with the urbanized area. The results showed the formation of islands of heat more expressive for the month of January with $4,89^{\circ} \mathrm{C}$ in urbanized area. The research also showed the need for a sustainable management of the Campus IV which takes into account such environmental parameters for spatial planning.
\end{abstract}

Keywords: Urban climatology, Island of heat, use and occupation of the soil

\section{INTRODUÇÃO}

Segundo Monteiro (1976), o primeiro estudo a respeito do clima urbano surgiu em Londres, por volta de 1833 e foi feito pelo climatologista Luke Howard, que percebeu contrastes meteorológicos entre a metrópole e o seu entorno. Dessa forma, esse foi o ponto de partida para que estudos relacionados a essa temática passassem a ser desenvolvidos em todo o mundo. Tal 
fato ocorreu justamente com o início da Revolução Industrial, que constituiu-se em um período marcado por grandes mudanças nos sistemas urbanos e também no sistema econômico onde as pessoas que viviam no campo se viram obrigadas a ir morar nos centros urbanos em busca de melhores empregos e condições de vida. Em consequência disso, ocorreu o crescimento das cidades e a transformação significativa do espaço geográfico de várias regiões. Algumas das transformações que ocorrem no espaço geográfico das áreas urbanas se representam através dos diferentes tipos de uso e cobertura do solo, que frequentemente ocasiona impermeabilização da parcela do solo urbano em substituição às áreas verdes por construções, aumentando assim, a rugosidade da superfície pelo adensamento dos edifícios e a verticalização que alteram o microclima desses ambientes e possibilitam a formação das ilhas de calor urbanas (SANTOS, et al., 2011).

Atualmente o estudo sobre o clima urbano se torna algo indispensável para o planejamento urbano e a gestão sustentável das cidades, tendo em vista, o ritmo acelerado do crescimento urbano sem o devido planejamento ambiental. Dentre todos os tipos de alterações climáticas que acontecem dentro das cidades, o fenômeno da ilha de calor é um dos mais evidentes. A ilha de calor urbana pode ser compreendida como um fenômeno típico das cidades que estão em crescente processo de urbanização. $O$ fenômeno se expressa melhor durante à noite apresentando temperaturas bem mais altas nos centros urbanos em relação as áreas adjacentes. O local de seu maior desenvolvimento coincide, com frequência, com o centro das cidades, onde as construções formam um conjunto mais densificado (BALBIRATO, 2007). As causas que contribuem para a formação da ilha de calor estão relacionadas às mudanças no balanço energético da superfície devida à urbanização. Sabe-se que, devido à sua natureza física particular, os centros urbanos podem ter temperaturas maiores que as áreas adjacentes, especialmente durante a noite e de maneira proporcional ao tamanho da cidade o que caracteriza a formação das ilhas de calor nesses ambientes (OKE, 1973). O uso de materiais escuros tanto nos edifícios como nos pavimentos também contribuem para uma maior absorção de calor e consequentemente formação de ilhas de calor. As temperaturas em superfícies escuras e secas podem chegar a $80{ }^{\circ} \mathrm{C}$ durante o dia, já as superfícies com vegetação e solo úmido sob as mesmas condições chegam a atingir apenas $18{ }^{\circ} \mathrm{C}$ (GARTLAND, 2010).

O fenômeno da ilha de calor pode ser classificado como um impacto das mudanças no meio urbano feito através das alterações humanas sobre a superfície terrestre. Para Givoni (1989) os 
principais fatores que causam as ilhas de calor são as diferenças no balanço total de radiação entre a área urbana e a rural, em particular a alta taxa de resfriamento durante a noite; armazenamento de energia solar nas edificações durante o dia que é desprendida durante a noite; produção concentrada de calor pelas atividades de transporte, indústria; baixa evaporação do solo e da vegetação em áreas densas e fontes sazonais de calor (aquecimento e resfriamento do ar com consequente desprendimento de calor para o ar urbano). Assim, a ilha de calor configura-se como um fenômeno decorrente do balanço de energia no espaço urbano, que se caracteriza através do acúmulo de calor nas superfícies e consequentemente a elevação da temperatura do ar, (BALBIRATO, 2007).

A cobertura vegetal é um importante elemento para a amenização climática em áreas urbanas e consequentemente para redução das ilhas de calor urbanas. Para Carvalho (2001), a amenização climática de um ambiente está relacionada diretamente com a cobertura vegetal do local. Ao realizar estudos sobre clima urbano e seus atenuantes, Honorato (2012) verificou que é preciso levar em consideração as características do solo, vegetação, recursos hídricos, meios de transportes, processos de uso e ocupação da área, dentre outros fatores, para efetuar alterações no microclima das cidades e combater a formação das ilhas de calor urbanas Vale salientar que a influência que uma cobertura vegetal exerce sobre o que chamamos de microclima urbano deve-se aos inúmeros benefícios fornecidos ao ambiente em que se encontra, seja ela composto de vegetação rasteira, arbustiva e arbórea.

Sendo assim, é diante deste contexto que esse artigo se insere, com o objetivo principal de realizar um estudo do clima urbano, especificamente campo térmico, dentro do espaço intra-urbano do Campus IV da Universidade Federal da Paraíba. A pesquisa procura correlacionar como as diversas formas de uso e coberturas do solo podem interferir na formação das ilhas de calor urbana na área de estudo. Dessa forma, espera-se que os resultados dessa pesquisa contribuam para uma gestão sustentável do Campus IV e leve em consideração a importância da climatologia urbana para o planejamento ambiental.

\section{METODOLOGIA}




\subsection{Delimitação da Área de Estudo}

A pesquisa foi realizada no espaço intra-urbano do Campus IV da Universidade Federal da Paraíba (UFPB), localizada no município de Rio TintolPB (figura 1), microrregião do Litoral Norte do Estado da Paraíba que fica entre as coordenadas geográficas 06³9'20" e 0656’40’'

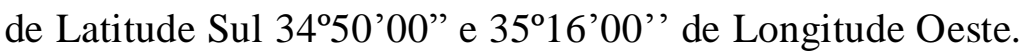
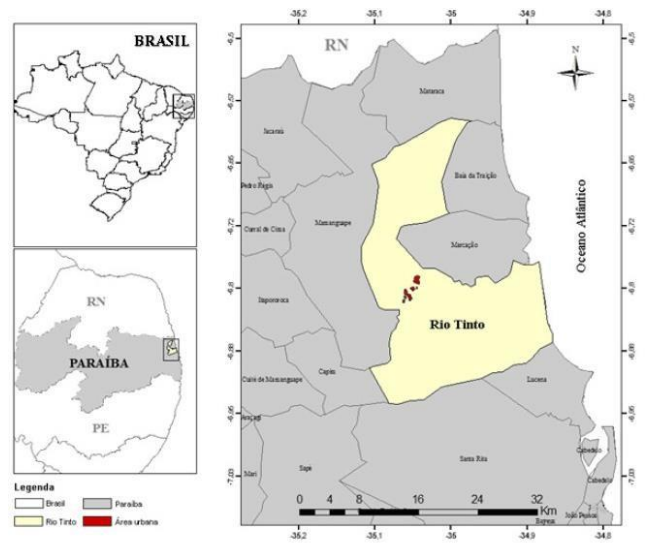

Figura 01. Localização geográfica do município de Rio Tinto onde está inserida a UFPB Campus IV.

Fonte: Freitas (2014).

O clima predominante é tropical chuvoso (com classificação Am, segundo Köeppen) com verão seco e condições climáticas caracterizadas por duas estações bem definidas, o de estiagem (agosto a fevereiro) e o chuvoso de ( março a julho). A média pluviométrica no período estudado foi de 112,73 mm (AESA, 2014) com clima predominantemente quente e úmido que permanece dentro da influência dos ventos alísios de sudeste durante todo o ano.

\subsection{Procedimentos Metodológicos}

Inicialmente foi feito um levantamento bibliográfico da temática em questão. Posteriormente foram definidos 05 pontos para coleta dos dados de temperatura e umidade relativa do ar. Para a coleta desses dados foram instalados termo-higrometros programados para realizar medições em intervalos horários ininterruptos. A periocidade para o monitoramento do microclima do espaço intra-urbano do Campus IV da UFPB ocorreu em dois períodos distintos: período de estiagem referente ao mês de janeiro de 2014 e o período chuvoso da área de estudo, referente ao mês de maio de 2014. As amostras experimentais foram definidas em função das diferenciações do uso e cobertura do solo. 
Para a avaliação da intensidade de ilha de calor (IC) urbana foi obtida a diferença entre a temperatura do ar da área não urbanizada (com cobertura vegetal densa) com as amostras mais urbanizadas (SILVA et al., 2010). Dessa forma, o ponto 02 (resquício de Mata Atlântica) foi considerado o ponto de referência para o estabelecimento da intensidade de IC. Para a verificação da ilha de calor urbana na área de estudo foram escolhidos dois meses representativos de cada período climático e avaliadas a formação e intensidade da ilha de calor urbana na escala horária.

Para a análise do clima urbano foi utilizada a metodologia apresentada por Monteiro (1976), onde são feitas medições in loco e a análise das variáveis climáticas de temperatura e umidade relativa do ar são correlacionadas com a descrição física do uso e cobertura do solo urbano.

\subsection{Caracterização física das amostras experimentais}

O campus IV da UFPB possui espaço intra-urbano amplo com uma biblioteca, salas de aula dispostas em vários blocos, diversos laboratórios, praças, estacionamento, residências universitária, restaurante universitário e auditório. Nesse espaço intra-urbano, estão localizados pontos de monitoramento dos dados microclimáticos (figura 03). São eles (p1) central de aulas, (p2) próximo ao fragmento de Mata (ponto de referência), (p3) praça central, (p4) biblioteca e (p5) bloco entre as residências universitárias.

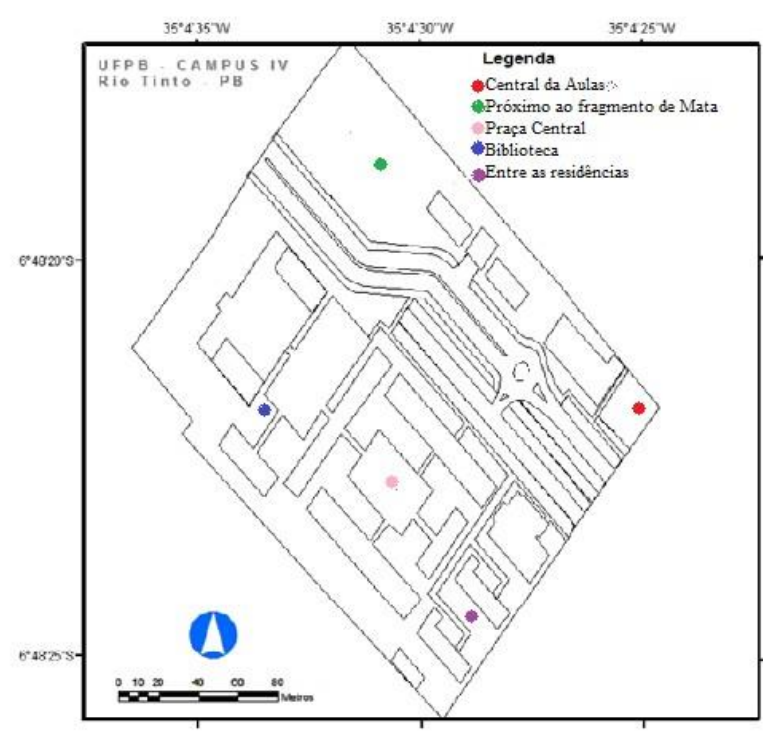

Figura 02. Campus IV da UFPB, unidade de Rio Tinto, com destaque para a localização dos pontos de coleta de dados. Fonte: Freitas (2014).

O ponto (p1)localizado em frente a Central de Aulas apresenta características do seu entorno com uso e cobertura do solo recoberto por materiais do tipo concreto e área construída. O (p2) 
está próximo a um fragmento de Mata Atlântica, essa amostra experimental foi tomada como o ponto de referência, pois suas características se assemelham as condições naturais da região antes da instalação do Campus IV. Nela verifica-se uma rica e densa cobertura vegetal, sendo ela arbustiva e arbórea. O (p3) está localizado na Praça Central do Campus IV da UFPB, essa amostra experimental apresenta solo totalmente recoberto por materiais do tipo concreto e área construída totalmente impermeabilizada, não apresenta cobertura vegetal e é cercada por edificações de um a dois pavimentos, atuando como barreira para a passagem do vento. O (p4) está localizado em frente à Biblioteca Central do Campus, essa amostra experimental apresenta solo impermeável e material de recobrimento do tipo: concreto, e em menor quantidade cerâmica e solo exposto, sem cobertura vegetal. Com isso, pode-se perceber que a maior parte do material de revestimento é impermeável e apresenta propriedades térmicas de retenção de calor e diminuição do albedo. Além disso, o seu entorno é caracterizado por edificações de um a dois pavimentos, impedindo a circulação do vento predominante (sudeste). O (p5) está localizado entre os blocos da residência universitária, essa amostra experimental apresenta parte do seu solo impermeável e solo exposto, com áreas construídas.

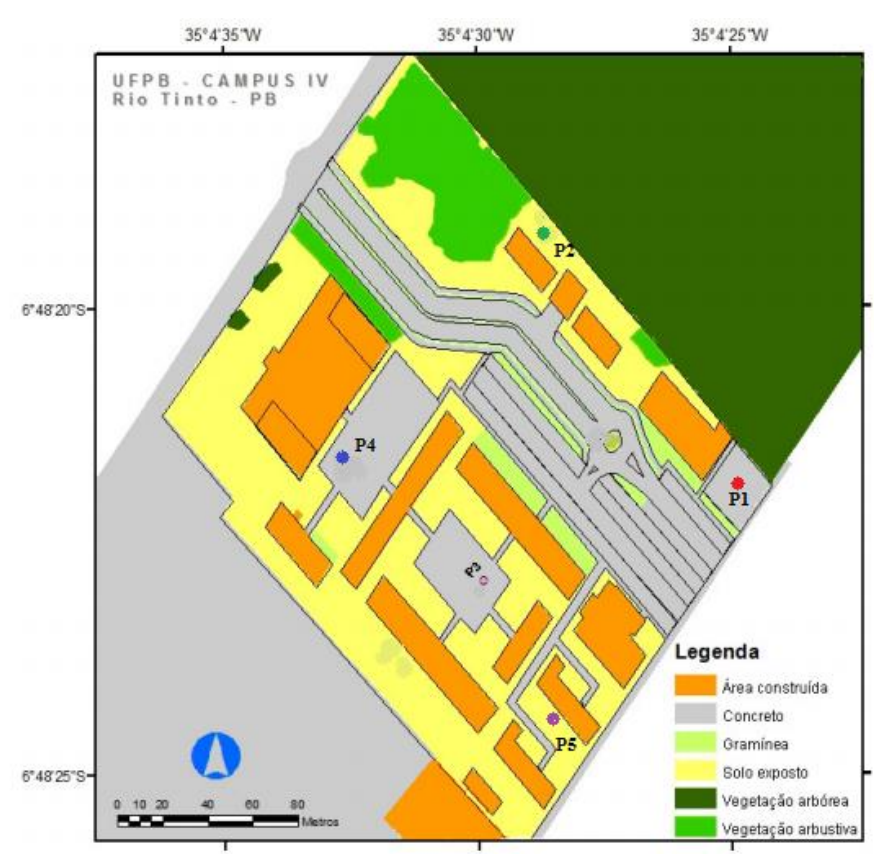

Figura 03. Distribuição espacial dos tipos de cobertura do solo no Campus IV da UFPB. Fonte: Freitas, (2014). 


\section{RESULTADOS E DISCUSSÃO}

De acordo com a caracterização do uso e cobertura do solo nos pontos monitorados, podese evidenciar que em sua maior parte estão em ambientes impermeabilizados por concreto e área construída, com exceção do (p2), que está próximo do resquício de Mata Atlântica. Pode-se dizer que à medida que os ambientes estão sendo modificados, havendo a substituição de áreas com vegetação por áreas construídas e impermeáveis, grandes modificações serão agravadas no meio ambiente, alterando assim o campo térmico urbano (Rocha, 2011).

\subsection{Comportamento da Ilha de Calor Urbana (ICU)}

A ilha de calor é um fenômeno formado em áreas urbanas pela constituição dos materiais de construção que absorvem e retêm mais calor da radiação solar do que áreas rurais ou menos urbanizadas, por possuírem materiais naturais (GARTLAND, 2010). Portanto, a intensidade de ilha de calor (IC) urbana foi obtida pela diferença entre a temperatura do ar da área com presença de vegetação e solo permeável (P5) com as áreas mais urbanizadas (P1, P2, P3 e P4).

No mês de janeiro, período referente ao de estiagem, a maior ICU atingiu $4,89^{\circ} \mathrm{C}$ às 08h00min no (p3). Silva, (2013) afirma que as superfícies urbanas se aquecem no decorrer do dia e durante a noite liberam o calor absorvido. A menor ilha de calor no mesmo período ocorreu no $(\mathrm{p} 1)$ às $11 \mathrm{~h} 00 \mathrm{~min}$ com $0,2^{\circ} \mathrm{C}$. Dessa forma a ICU oscilou entre $4,89^{\circ} \mathrm{C}$ e $0,2^{\circ} \mathrm{C}$ apresentando uma amplitude de $4,69^{\circ} \mathrm{C}$ no espaço intra-urbano da área de estudo (Figura 04). A maior temperatura registrada no período de coleta foi de $33,9^{\circ} \mathrm{C}$ no mês de janeiro no (P5), onde o mesmo apresenta parte do seu solo recoberto por materiais impermeáveis.

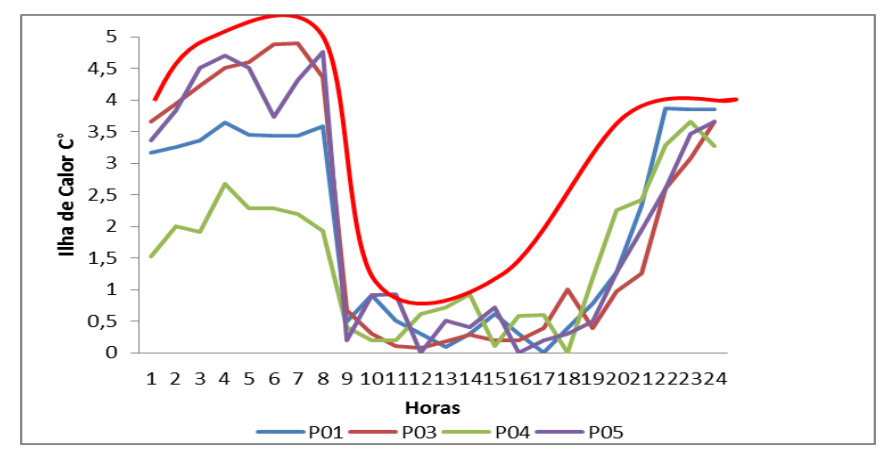

Figura 04. Comportamento da ICU no dia monitorado referente ao período de estiagem /Janeiro. 
As características físicas e dos materiais de recobrimento: blocos de dois pavimentos, solo recoberto por concreto e grama espaçada existente no (P3) influenciou em uma maior concentração de energia nesse local. Já (p1) que obteve a menor ICU está localizado em frente a central de aulas do Campus e apresenta solo recoberto por concreto e cerâmica, mas também está próximo de um fragmento de Mata Atlântica favorecendo assim a ventilação local, a taxa de umidade relativa do ar e consequentemente a amenização climática.

Durante o mês de janeiro a precipitação foi de $29,2 \mathrm{~mm}$, também considerada baixa, porém vale destacar que o mês de janeiro é o mais representativo no período de estiagem, favorecendo assim a alta intensidade da ICU.

Pode-se observar também na (figura 04), o padrão horário da intensidade das ilhas de calor nas amostras experimentais. Verifica-se que entre às 01h:00 min e 08h:00min da manhã as ICU's permaneceram altas, e a partir das 9h:00min até às 19h:00min elas per maneceram baixas, voltando a subir novamente entre às 20h:00min e 00h:00min. Filho (2011), também encontrou padrão semelhante em estudo realizado em Fortaleza-CE, onde as ilhas de calor foram mais intensas durante a noite, atingindo até $3,0^{\circ} \mathrm{C}$. Vale destacar, que durante o dia os materiais sólidos absorvem calor e liberam durante a noite, evidenciando assim, as maiores ilhas de calor neste período noturno.

No mês de maio, período referente ao chuvoso, a maior ICU atingiu $3,7^{\circ} \mathrm{C}$, também (p3) às $17 \mathrm{~h}: 00 \mathrm{~min}$. O (p3) está localizado na praça, onde o solo não apresentava nenhuma cobertura vegetal, possui sua área toda é impermeabilizada e rodeada de prédios. Já a menor ICU foi de $0,1^{\circ} \mathrm{C}$ no (p1), localizado próximo a um resquício de Mata Atlântica, às 08h:00min. De acordo com esses dados, obteve-se uma amplitude térmica de $3,6^{\circ} \mathrm{C}$. Interessante perceber que valores semelhantes foram encontrados para cidades de grande porte como São Paulo e Porto Alegre (MENDONÇA, 2003). Para este mês a média pluviométrica foi de 158,5mm, evidenciando uma maior taxa de precipitação para a área de estudo, fazendo com que as intensidades das ilhas fossem menores nesse mês. Vale destacar que a menor temperatura registrada no período de coleta foi de $19,5^{\circ} \mathrm{C}$ no mês de Maio no (P2), aquele que possui características mais próximas de um ambiente rural. 


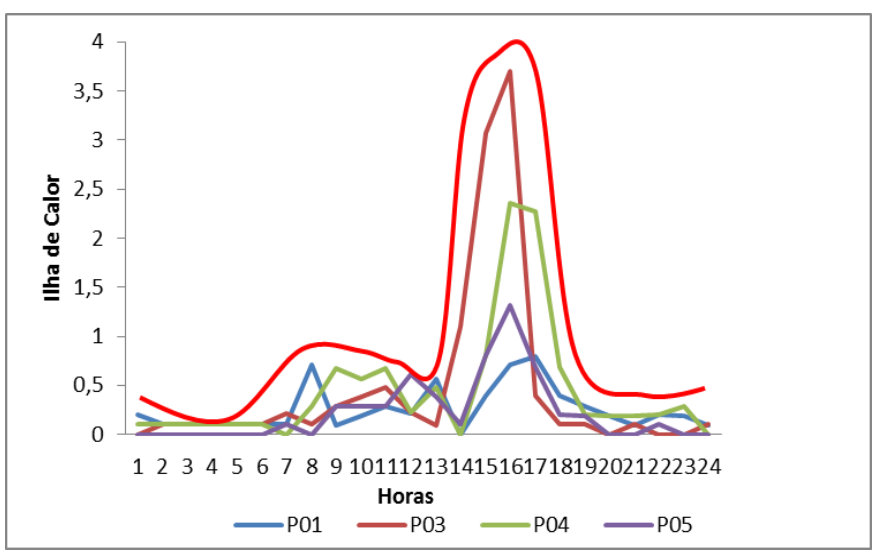

Figura 05. Comportamento da ICU no dia monitorado referente ao período chuvoso/ Maio

No período analisado, pode-se também observar alguns padrões horários nas ICU's. Verifica-se que entre 01h:00min e 13h:00min as ilhas permaneceram com intensidades baixas e entre 14h:00min e 18h:00min elas permanecem mais intensas, voltando a diminuir a partir das 19:00h. Esse fato demonstra que o papel da precipitação nesse período foi de "mascarar" os valores das ilhas, invertendo os padrões evidenciados no período seco da área de estudo. Em trabalho realizado na cidade de João Pessoa menores ilhas de calor foram encontradas no período chuvoso em contraste com o período seco.

\section{CONSIDERAÇÕES FINAIS}

Os resultados obtidos através das análises do campo térmico urbano e sua relação com o uso e cobertura do solo no espaço intra-urbano do Campus IV permitem concluir que a composição do material de recobrimento do espaço intra-urbano do Campus IV da UFPB exerce grande influência no comportamento da temperatura e umidade relativa do ar. A menor temperatura registrada no período de coleta foi de $19,5^{\circ} \mathrm{C}$ no mês de Maio no (P2), aquele que possui características mais próximas de um ambiente rural. E a maior temperatura registrada foi de $33,9^{\circ} \mathrm{C}$ (mês de Janeiro) no (P5), onde o mesmo apresenta parte do seu solo recoberto por materiais impermeáveis. A análise da ICU foi considerada relevante, pois em cada um dos

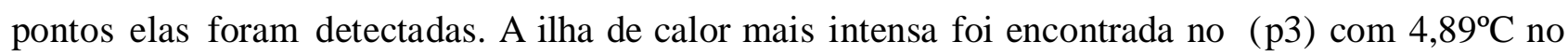
período de estiagem, demonstrando assim a necessidade de uma intervenção para que esse efeito seja minimizado, podendo o ser o plantio de árvores uma delas. O horário de pico das ICU's se estabeleceu entre às 08h:00min até ás 19h:00min durante o período seco. Vale ressaltar que as ICU's no período de estiagem ocorreram durante a noite ou no início da manhã, ressaltando assim 
que as superfícies começam a liberar a energia nesse período. Já no período chuvoso as ilhas de calor ocorreram durante o período da tarde e início do período noturno. As ilhas de calor foram menores durante o período chuvoso, pois a precipitação amenizou a intensidade das icu's. Além disso, a pesquisa também demonstrou a necessidade de uma gestão sustentável do Campus IV, que leve em consideração conhecimentos do campo científico da Climatologia Urbana. Tais parâmetros ambientais devem ser levados em consideração para o ordenamento territorial. Com isso, espera-se que haja intervenções dentro do espaço intra-urbano do Campus IV da UFPB, visando melhorias no planejamento ambiental e urbano da área de estudo.

\section{REFERÊNCIAS}

AESA (Agência Executiva De Gestão Das Águas Do Estado Da Paraíba) - $\quad$ Disponível em <site2.aesa.pb.gov.br/aesa/jsp/monitoramento/chuvas/chuvas/DiariasMapa.jsp\#> Acesso em $22 \mathrm{de}$ novembro de 2014.

BAlbirato G M. 2007. Clima E Cidade: A Abordagem Climática Como Subsídio Para Estudos Urbanos, Págs. 71 e 76.

CARVALHO, M. M. Clima urbano e vegetação: estudo analítico e prospectivo do parque das dunas em natal, 2001.

DA SILVA, V. P. R.; AZEVEDO, P. V.; BRITO, R. S.; CAMPOS; J. H. B. C. Evaluating the urban climate of a typically tropical city of northeastern Brazil. Environ Monit Assess., v. 161, n.1-4,p. 45-59, 2010

FILHO, F de A, L. Monografia em graduação em Física, pela UFCE. Estudo numérico de ilha de calor em Fortaleza utilizando o modelo rams, 2011.

FREITAS, A, F SANTOS, J, S; ALMEIDA, N, V. Avaliação do conforto térmico do Campus IV- Rio Tinto aplicado ao ordenamento territorial ambiental. Revista Caminhos de Geografia. Uberlândia. 2014.

GIVONI, B. Urban design in diferente climates. Los Angeles, World Metereological Organization (WMO/TD-n. 346, WCAP-10), 1989.

GARTLAND, L. Ilhas De Calor - Como Mitigar Zonas De Calor Com Áreas Urbanas, Editora Oficina De Textos, 2010.

HONORATO, A. F. A. Ilhas De Calor E Frescor Na Área Urbana Da Cidade De Aquidauan, Ms.Revista Geonorte, Edição Especial, V.2, N.4, P.878 - 886 ,2012.

MONTEIRO, C.A. de F. Teoria e Clima Urbano. In: Série Teses e Monografias, n.25 - Instituto de Geografia, Faculdade de Filosofia, Letras e Ciências Humanas, Universidade de São Paulo, São Paulo, 1976.181p. 
MENDONÇA, C.A. Clima e planejamento urbano em Londrina. In: MONTEIRO, C. A de F.;MENDONÇA, F.(Org.). Clima Urbano. São Paulo: Editora Contexto, 2003. 192p. p.93-12

ROCHA, L, M, V; SOUZA, L, C, L; CASTILHO, F, J, V. Ocupação do solo e ilha de calor noturna em avenidas marginais a um córrego urbano. Revista Ambiente Construído. Ano VI, n.3. Porto Alegre 2011.

SANTOS, J, S. Tese de Doutorado no programa de pós graduação em recursos naturais pela UFCG. Campo térmico urbano e a sua relação com o uso e cobertura do solo em uma cidade tropical úmida. 2011.

SANTOS, J, S; SILVA, V, P, R; ARAÚJO, L, E; LIMA, E, R, V; COSTA, A, D, L. Análise Das Condições Do Conforto Térmico Em Ambiente Urbano: Estudo De Caso Em Campus Universitário. Revista Brasileira De Geografia Física. V. N. 2:336-353. 2011.

SILVA, I, A; VIEIRA, M, L, S; SANTOS, J, S; ARAÚJO, L, E. Clima urbano: uma avaliação do campo térmico urbano do campus iv da ufpb\Rio Tinto-PB. Revista Brasileira de Geografia Física,Vol. 6, No 5.2013.

OKE,T ,R. City Size and The Urban Heat Island. Atmospheric Environment, v.7, p. 769-779,1973.

\section{AGRADECIMENTOS}

Agradecemos à Universidade Federal da Paraíba, ao Programa de Pós Graduação em Desenvolvimento e Meio Ambiente e á Capes pelo incentivo á pesquisa e auxilio financeiro.

Recebido em: 14/08/2016

Aceito para publicação em: 01/10/2016 